\title{
A RESPONSABILIDADE PENAL AMBIENTAL NA CONSTITUIÇÃO DA REPÚBLICA FEDERATIVA DO BRASIL DE 1988
}

\section{ENVIRONMENTAL CRIMINAL LIABILITY IN THE 1988 CONSTITUTION OF THE FEDERATIVE REPUBLIC OF BRAZIL}

\section{Volnei Celso Tomazini ${ }^{1}$}

Resumo: Este artigo científico trata da Responsabilidade Penal Ambiental na Constituição da República Federativa do Brasil de 1988, sob um olhar eminentemente acadêmico, eis que visa a atender um dos critérios de avaliação para o aproveitamento do discente na disciplina Teoria do Estado e da Constituição do curso de doutorado em Ciência Jurídica da Univali. Demonstra-se os conceitos operacionais sobre as categorias Constituição, Meio Ambiente e Responsabilidade Penal Ambiental. Aborda-se a relevância do próprio tema aqui proposto para a proposta acadêmica, bem como a sua relevância para conscientização da Sociedade sobre os efeitos da responsabilização penal aos poluidores previstos no art. 225 , da Constituição da República Federativa do Brasil de 1988.

Palavras-Chave: Constituição. Meio ambiente. Responsabilidade penal ambiental.
Abstract: This scientific paper deals with Environmental Criminal Liability in the 1988 Constitution of the Federative Republic of Brazil, under an eminently academic view, for it aims at meeting one of the assessment criteria for the use of the student on the State and Constitution Theory subject of the doctorate course in Legal Sciences from Univali. The operational concepts about the categories Constitution, Environment and Environmental Criminal Liability are demonstrated. The relevance of the theme hereby proposed for the academic proposal itself is approached, as well as its relevance for the awareness of Society on the effects of criminal liability of polluters stipulated in article 225 of the 1988 Constitution of the Federative Republic of Brazil.

Keywords: Constitution. Environment. Environmental criminal liability.

1 Mestre e doutorando em Ciência Jurídica pela Universidade do Vale do Itajaí (Univali). Magistrado com atuação no Tribunal de Justiça de Santa Catarina.

E-mail: volnei@tjsc.jus.br 


\section{INTRODUÇÃO}

Devido à relevância do tema para o estudo da Constituição e/ou do Estado no Século XXI, este Artigo Científico se propõe a analisar a Responsabilidade Penal do agente poluidor, prevista no $\S 3^{\circ}$, do art. 225 da Constituição da República Federativa do Brasil de 1988 (BRASIL, 1988).

A proposição temática deste Artigo Científico divide-se em três partes. A primeira parte dispõe sobre a importância do Conceito Operacional da Categoria ${ }^{2}$ Constituição para demonstrar a importância que o legislador constituinte conferiu ao tema Meio Ambiente, alçando-o ao privilégio de constar no âmbito hierárquico legislativo na condição de status constitucional.

A segunda parte preocupa-se com o Conceito Operacional da Categoria Meio Ambiente e sua relevância para a Sociedade Contemporânea. A visão dos juristas que propõem o direito ao Meio Ambiente equilibrado e protegido constitucionalmente como Direito Fundamental. Nessa condição, aborda-se o direito ao Meio Ambiente equilibrado com um Direito à Dignidade da Pessoa Humana de todo o cidadão.

Na terceira e última parte, descreve-se a Responsabilidade Penal dos agentes poluidores do Meio Ambiente cuja previsão legal consta do $\S 3^{\circ}$, do art. 225 da Constituição da República Federativa do Brasil (BRASIL, 1988).

Para a elaboração deste Artigo Científico, utilizou-se o Método Indutivo tanto na fase investigativa como na fase de relatório do resultado das pesquisas, operacionalizando-se as Técnicas do Referente ${ }^{3}$, da Categoria, do Conceito Operacional e da Pesquisa Bibliográfica.

2 “[...] palavra ou expressão estratégica à elaboração e/ou à expressão de uma ideia." (PASOLD, 2013, p. 31).

3 Referente para a elaboração do presente Artigo Científico: Informações, conhecimentos e reflexões úteis para a Tese de Doutoramento. 


\section{CONCEITO DE CONSTITUIÇÃO}

Diferentes são os posicionamentos para se compreender e interpretar a Constituição de um Estado. Pode-se analisá-la por meio de uma concepção sociológica, política, jurídica, cultural e até mesmo religiosa ou teológica ${ }^{4}$.

A Categoria Constituição é um termo polissêmico, ou seja, admite mais uma interpretação, mas para fins desta pesquisa, afirma-se que se trata de uma norma especial que o Poder Constituinte elabora por delegação e representação do povo. No Estado Democrático de Direito, a Sociedade delega representação ao Poder Constituinte, modalidade de representação própria dos países federativos para a elaboração da Lei Maior.

No âmbito jurídico, Constituição é a Lei Fundamental e Suprema de um Estado ${ }^{5}$, constituída de normas referentes à sua estruturação, a formação dos poderes públicos, forma de governo e aquisição de poder de governar, distribuição de competências, direitos, garantias e deveres dos cidadãos, além de individualizar os órgãos competentes para a adição de normas jurídicas, legislativas ou administrativas (MORAES, 2002, p. 83).

Para Heller, o termo Constituição possui maior amplitude do que a Lei Fundamental do Estado de forma escrita. "A Constituição de um Estado coincide com a sua organização enquanto esta significa a constituição produzida mediante atividade humana consciente e só ela." (HELLER, 1968, p. 295).

Heller distingue conceitos de Constituição de natureza sociológica e de natureza jurídica. Nesse sentido, Bester explicitou de forma sintética a conceituação de Heller, nos seguintes termos:

Dentro da pluralidade de possibilidades conceituais a res-

4 Para a presente pesquisa limita-se a análise da Constituição sob uma concepção eminentemente jurídica. A abordagem visa analisar o termo de Constituição pela sua relevante contribuição para abrigar o tema que é objeto do presente Artigo Científico.

5 Na concepção de Pasold "o Estado deve ser um conjunto de atividades legítimas efetivamente comprometidas com uma função Social” (PASOLD, 2013, p. 89). 
peito do que é uma Constituição, envolvendo uma diversidade de tipológicas díspares, analisamos, mesmo que em linhas gerais, as que se enquadram no "sociologismo", no "voluntarismo decisionista", e no "dever-ser da teoria pura". E o fizemos para chegarmos ao esforço dialético e pleno de Hermann Heller, o qual intentou unir o mundo do ser e do dever ser. Isso quer dizer que, para Heller, a Constituição só poderia ser entendida em uma acepção total e o seu conceito de Constituição política total abarcou dois elementos imprescindíveis para tal "totalidade" (a "constituição não normada" e a "constituição normada"). Frisa-se que Heller retornou o controle sociológico de Constituição firmado por Lassale ("soma dos fatores reais de poder") e completou-o, unindo o mundo do ser com o do dever-ser. (BESTER, 1999, p. 231-250).

Por sua vez, a Constituição normada pode sê-la jurídica e extrajuridicamente e esta normação extrajurídica consiste em "princípios éticos de direito", tais como o costume, a moral, a religião, a urbanidade e a moda (BESTER, 1999, p. 231-250).

A interpretação constitucional será feita conforme os fatores sociais, mantidos permanentemente atualizados contribuindo para a permanência da própria Norma Constitucional, independentemente da evolução do tempo e das pessoas no entender do renomado constitucionalista (BESTER, 1999, p. 231-250).

Norberto Bobbio define o termo num sentido descritivo ao afirmar que Constituição é "a própria estrutura de uma comunidade política organizada, a ordem necessária que deriva da designação de um poder soberano e dos órgãos que o exercem". (BOBBIO, 1997, p. 247).

Barroso consigna que numa perspectiva moderna e liberal, a Constituição não tem caráter meramente descritivo das instituições, pois pretende influenciar sua ordenação, mediante um ato de vontade e de criação expresso em documento inscrito. (BARROSO, 2015, p. 99). 
Para José Afonso da Silva,

A Constituição do Estado, considerada sua lei fundamental, seria, então, a organização de seus elementos essenciais: um sistema de normas jurídicas, escritas ou costumeiras, que regula a forma do Estado, a forma de seu governo, o modo de aquisição e o exercício do poder, o estabelecimento de seus órgãos, os limites de sua ação, os direitos fundamentais do homem e suas respectivas garantias. Em síntese, a Constituição é o conjunto de normas que organiza os elementos constitutivos do Estado. (SILVA, 2014, p. 39-40).

Eros Roberto Grau, sob o viés específico, citando Vital Moreira, mencionou uma ideia de Constituição Econômica sob o argumento de que seu Conceito Operacional já não mais comporta uma concepção em termos mais amplos, aduzindo-a como:

O conjunto de preceitos e instituições jurídicas que, garantindo os elementos definidores de um determinado sistema econômico, instituem uma determinada forma de organização e funcionamento da economia, e constituem, por isso mesmo, uma determinada ordem econômica. (GRAU, 2015, p. 77).

A Constituição da República Federativa do Brasil de 1988 é fruto de ampla discussão popular. O legislador constituinte incluiu no seu texto os Direitos Sociais para contemplar a plena cidadania aos brasileiros. Trata-se de uma Constituição escrita, promulgada, rígida, formal e dogmática.

De acordo com a teoria de Castro e Mezzaroba, a Carta Magna:

Não é uma carta híbrida, eclética nem dual, porque não se limita a conciliar interesses individuais e sociais. $\mathrm{O}$ que existe é algo novo, elevado a novo patamar, em que a sociedade é colocada no centro gravitacional do debate e os direitos individuais são exercidos para o bem da coletividade. Nela, pode-se identificar um claro programa de construção de uma sociedade melhor, livre, justa e solidária, como declara a própria Constituição de 1988. (CASTRO; MEZZAROBA, 2015, p. 141). 
A Responsabilidade por Dano Ambiental consta da Constituição da República Federativa do Brasil de 1988 como direito e garantia de todo o cidadão, nos termos do que leciona José Afonso da Silva, ao dispor:

As constituições têm por objeto a estrutura do Estado, a organização de seus órgãos, o modo de aquisição do poder e a forma de seu exercício, limites de sua atuação, assegurar os direitos e garantias dos indivíduos, fixar o regime político e disciplinar os fins socioeconômicos do Estado, bem como os fundamentos dos direitos econômicos, sociais e culturais. (SILVA, 2015, p. 77).

No parâmetro desta evolução conceitual, afirma-se que a Constituição da República Federativa do Brasil de 1988, detém plena legitimidade para abrigar o tema da Responsabilidade Penal Ambiental aos agentes causadores de dano ao Meio Ambiente.

\section{RELEVÂNCIA E CONCEITO DE MEIO AMBIENTE}

No passado, o termo "sustentabilidade" ${ }^{\text {" }}$ praticamente não constava do vocabulário do cotidiano das pessoas. Eventual agressão ao Meio Ambiente não surtia efeitos relevantes junto às comunidades, pois o número de habitantes, em comparação com a extensão territorial do planeta, era insignificante. Inexistia preocupação com a escassez de recursos hídricos, minerais ou de outra natureza; a oferta de recursos naturais era abundante e a sua respectiva degradação era praticamente imperceptível.

Prevalecia a indiferença quanto à adoção ou não de ações que

6 Freitas propõe um conceito para o princípio da sustentabilidade: "trata-se de princípio constitucional que determina, com eficácia direta e imediata, a responsabilidade do Estado e da sociedade pela concretização solidária do desenvolvimento material e imaterial, socialmente inclusivo, durável e equânime, ambientalmente limpo, inovador, ético e eficiente, no intuito de assegurar, preferencialmente de modo preventivo e precavido, no presente e no futuro, o direito ao bem estar." (FREITAS, 2012. p. 41). 
comprometiam a subsistência do Ecossistema. Predominavam os meios de produção e exploração primários, o que limitava a expansão territorial para o manejo e exploração da agricultura, pecuária e extração de matéria-prima do solo. Subestimava-se, portanto, a política de preservação do Meio Ambiente, pois o perigo dos efeitos de sua degradação era desconhecido.

As primeiras percepções das consequências dessa omissão, quanto à preservação do Ecossistema, surgiram a partir da Revolução Industrial, ocorrida na Europa no século XVI, quando, a euforia progressista com o processo de transformação da matéria-prima em produto final, demonstrava a reprovação das ações direcionadas ao lamentável comprometimento da Sustentabilidade do planeta.

A preocupação com a preservação do Meio Ambiente é recente na história da humanidade. Ela ocorre no fim do século passado. Ocasião em que a omissão e o descaso com a preservação do Ecossistema produziu os primeiros desastres ambientais em nosso habitat. Até então, não existiam políticas públicas de preservação, não existiam legislações de proteção à altura da gravidade dos problemas que surgiram em decorrência da ausência de conscientização sobre uma política de proteção ecológica da humanidade.

Gradualmente, os efeitos da agressão ao Meio Ambiente sensibilizaram algumas pessoas. A Sociedade passou a se organizar por meio de associações, organizações não governamentais e agremiações partidárias. Os partidos políticos passaram a incluir propostas de preservação e políticas de proteção ambiental em seus programas partidários. Tem início, assim, a sensibilização humana sobre a importância da adoção de ações de proteção ao Meio Ambiente sustentável.

No Brasil, a exemplo de outros países, surgiram movimentos de apoio à defesa do Meio Ambiente. Serviu de inspiração 
o grande marco que ocorreu em 1972, em Estocolmo, capital da Suécia, com a realização da Conferência das Nações Unidas sobre o Meio Ambiente Humano. Esse evento teve contribuição decisiva para a conscientização, por parte dos governantes, quanto a adoção de políticas preservacionistas. Intensifica-se, assim, o interesse no aperfeiçoamento e elaboração de leis ambientais no ordenamento jurídico dos países signatários dos compromissos firmados no respectivo evento. ${ }^{7}$

A partir daí, a ideia da importância do desenvolvimento sustentável teve avanços significativos para o futuro da humanidade e, pela primeira vez o Brasil promoveu, em 1992, a Conferência das Nações Unidas sobre o Meio Ambiente e o Desenvolvimento, também conhecida como "Eco-92". Esse evento ocorreu no Rio de Janeiro e tornou-se mundialmente conhecido pela sua significativa importância e repercussão na mídia em geral. Diante de tal relevância, a conferência resultou na elaboração de novos documentos dotados de propostas e recomendações sobre políticas de proteção ao Meio Ambiente.

Atualmente, a temática "preservação do Meio Ambiente" já é consenso nas Sociedades atuais. São significativos os avanços legislativos em vários países no sentido de se promover, a inclusão de medidas de proteção ao Meio Ambiente, como Função Social do Estado Contemporâneo. No Brasil, os avanços ocorridos nas últimas décadas, nessa área, também são percebíveis.

Castro e Mezzaroba mencionam que a Constituição da República Federativa do Brasil de 1988

Contemplou um capítulo destinado ao meio ambiente ecologicamente equilibrado para a presente e para as futuras gerações, medida esta fruto de um tempo no qual a degra-

7 Dessa conferência também surgiram propostas e compromissos que influenciaram o legislador constituinte de 1988 a inserir na Carta Magna do Brasil preceito protecionista que retratava a preocupação da Sociedade brasileira com causa ambiental em seu território. 
dação do planeta, imposta pelo modelo de industrialização adotado no passado pelas nações de capitalismo central acarretou poluição, extinção de espécimes animais, vegetais e minerais, destruição e morte. (CASTRO; MEZZAROBA, 2015, p. 140-141).

Pasold destaca a importância do tema Meio Ambiente para fins de compor uma pauta de discussões sobre a composição da Teoria do Estado e a Teoria da Constituição para o século XXI.

Há bastante tempo (desde 1983) defendo que a Função Social que o Estado contemporâneo deve ter e cumprir somente se viabilizará caso, entre outros requisitos, da prioridade para a realização de valores fundamentais do Homem (com a coerente atuação em favor do Meio Ambiente, Saúde, Educação, Trabalho, Liberdade, Igualdade). Por essas fundadas razões, o Meio Ambiente deve estar sempre ocupando posição central, nodal, essencial no disciplinamento de qualquer atividade individual ou coletiva. É este primeiro componente estratégico do quadro que deve ser implantado no Tempo XXI. (PASSOLD, 2013, p. 76, grifo do autor).

A legislação brasileira tratou da definição do Conceito Operacional de Meio Ambiente ${ }^{8}$, no art. $3^{\circ}$, inciso I, da Lei ${ }^{\circ}$ 6.938/81 (Lei da Política Nacional do Meio Ambiente), ao dispor como "o conjunto de condições, leis, influências e interações de ordem física, química e biológica, que permite abrigar e reger a vida em todas as suas formas". (BRASIL, 1988).

A Constituição da República Federativa do Brasil de 1988 dispõe em seu art. $225^{9}$, caput, sobre a conceituação da Categoria Meio ambiente, neste sentido:

8 Em que pese o termo Meio Ambiente não apresentar consenso na doutrina, pois "meio" seria conceituado como o centro de algo e "ambiente" seria o meio onde vivemos. Estaríamos, portanto, diante de uma redundância. Mas, como a categoria Meio Ambiente encontra-se amplamente presente na redação de livros, periódicos, pareceres, acórdãos e jurisprudências não restam dúvidas de que esta categoria consolidou-se na literatura jurídica brasileira.

9 Embora não conste do Capítulo II, art. $6^{\circ}$, da Constituição Federal, o constituinte reservou posição ao direito ao Meio Ambiente no título da Ordem Social, sendo que isto não ameniza a importância de tal instituto, pois é inconteste o interesse público de que reveste-se tal instituto. 
Todos têm direito ao meio ambiente ecologicamente equilibrado, bem de uso comum do povo, e essencial à sadia qualidade de vida, impondo-se ao Poder Público e à coletividade o dever de defendê-lo e preservá-lo para as presentes e futuras gerações. (BRASIL, 1988).

Observa-se que o comando normativo citado menciona o pronome indefinido "todos", logo, a ideia é de inclusão geral de beneficiários. Incluem-se todos os brasileiros natos, naturalizados os estrangeiros que residem ou encontram-se transitoriamente no Brasil. Trata-se de Direito Público subjetivo, individual ou coletivo, de vontade autônoma e livre, isto é, o direito de acionar o Poder Público para exigir a garantia de um direito, no caso específico, o Meio Ambiente ecologicamente equilibrado.

Para Melo, Meio Ambiente é o "conjunto de condições naturais de uma determinada área geográfica que interagem com os seres vivos, garantindo-lhes a sobrevivência" (MELLO, 2000, p. 64).

Meio Ambiente ecologicamente equilibrado é o habitat sem poluição, salubre, ou seja, que fornece as condições ao cidadão possuir uma qualidade de vida saudável. Trata-se de direito indisponível, ou seja, o indivíduo não pode dispor do direito sem restrições de ordem legal em face do interesse público de que é revestido. Trata-se de bem de uso comum do povo, pois o Meio Ambiente pertence a todos, direito difuso porque não é divisível, cujas pessoas titulares não se pode determinar, bem jurídico autônomo e essencial à sadia qualidade de vida.

Na concepção de Marcelo Abelha Rodrigues:

Pode-se dizer que se protegem os elementos bióticos e abióticos e sua respectiva interação, para se alcançar a proteção do meio ambiente ecologicamente equilibrado porque este bem é responsável pela conservação de todas as formas de vida. Possui importância fundamental a identificação do meio ambiente ecologicamente equilibrado como sendo 
um bem autônomo e juridicamente protegido, de fruição comum (dos elementos que o formam), porque, em última análise, o dano ao meio ambiente é aquele que agride o equilíbrio ecológico, e uma eventual reparação deve ter em conta a recuperação desse mesmo equilíbrio ecológico. (RODRIGUES, 2002, p. 58).

José Afonso da Silva apresenta um Conceito Operacional para a Categoria Meio Ambiente como sendo "a inteiração do conjunto de elementos naturais, artificiais e culturais que propiciem o desenvolvimento equilibrado da vida em todas as suas formas". (SILVA, 1998, p. 2).

E o mencionado constitucionalista vai mais além, ao preconizar:

O conceito de meio ambiente há de ser, pois, globalizante, abrangente, de toda a Natureza original e artificial, bem como os bens naturais correlatos, compreendendo, portanto, o solo, a água, o ar, a flora, as belezas naturais, o patrimônio histórico, artístico, turístico, paisagístico e arqueológico. O meio ambiente é, assim, a interação do conjunto de elementos naturais, artificiais e culturais que propiciem o desenvolvimento equilibrado da vida em todas as suas formas. A integração busca assumir uma concepção unitária do ambiente, compreensiva dos recursos naturais e culturais. (SILVA, 1998, p. 2).

Depreende-se, assim, por meio da análise desses Conceitos Operacionais a preocupação com a abrangência e a relevância do tema Meio Ambiente para a doutrina. Constitui-se, então, num indispensável pressuposto para a sobrevivência dos seres vivos na Terra. Ao se posicionar diante de um fator que desenvolve uma condição natural para a preservação dos seres vivos, podemos alçar o direito ao Meio Ambiente entre aqueles que são considerados fundamentais. Direito ao Meio Ambiente equilibrado constitui-se em Direito à Vida como um Direito Fundamental previsto na Constituição da República Federativa do Brasil, em seu art. 5º caput (BRASIL, 1988). 
Os Direitos Sociais constituem-se em prestações positivas estatais constantes de normas constitucionais que possibilitam melhores condições de vida aos mais necessitados, direitos que tendem a tornar iguais situações sociais diferentes. Valem como pressupostos do gozo dos direitos individuais porque criam condições materiais mais propícias ao aferimento da igualdade social. (SILVA, 1982, p. 253).

Direito à Vida consta entre os Direitos Fundamentais da Pessoa Humana, logo, posiciona-se entre os de maior relevância porque o direito de sobrevivência do homem abrange outros direitos, como o Direito à Vida e o Direito à Dignidade da Pessoa Humana. Logo, somente serão preservados a vida e o Direito de Dignidade com políticas de preservação do Meio Ambiente em equilíbrio.

O direito a um ambiente equilibrado e saudável como um dos direitos da personalidade, consta da doutrina de Luiz Roberto Barroso, ao preconizar: "A dignidade humana é um conceito valioso, com importância crescente na interpretação constitucional, e que pode desempenhar um papel central na fundamentação de decisões envolvendo questões oralmente complexas." (BARROSO, 2014, p. 11).

O Direito ao Meio Ambiente identifica-se com o elemento da Dignidade Humana ${ }^{10}$. Na acepção de Barroso: "A dignidade como valor comunitário enfatiza, portanto, o papel do Estado e da comunidade no estabelecimento de metas coletivas e de restrições sobre direitos e liberdades individuais em nome de certa concepção de vida boa." (BARROSO, 2014, p. 88).

Ingo Sarlet preconiza o termo Dignidade da Pessoa Humana com sendo

A qualidade intrínseca e distintiva reconhecida em cada ser

10 Conforme a doutrina de Luiz Roberto Barroso, ele identifica três elementos como parte do núcleo essencial da dignidade humana: Valor intrínseco, autonomia e valor comunitário. (Vide: BARROSO, 2014. p. 76-98). 
humano que o faz merecedor do mesmo respeito e consideração por parte do Estado e da comunidade, implicando, neste sentido, um complexo de direitos e deveres fundamentais que assegurem à pessoa tanto todo e qualquer ato de cunho degradante e desumano, como venham a lhe garantir as condições existenciais mínimas para uma vida saudável, além de propiciar e promover sua participação ativa e corresponsável nos destinos da própria existência e da vida em comunhão com os demais seres humanos, mediante o devido respeito aos demais seres que integram a rede da vida. (SARLET, 2015, p. 70-71).

Busca-se, assim, reconhecer a qualidade que se confere a cada ser humano que consiste no respeito e consideração por parte de todos, quer seja do Estado, dos demais integrantes da Sociedade para fins de se garantir um complexo de direitos e deveres. Todos merecem proteção contra qualquer ato de cunho degradante e desumano. O Estado deve prover condições mínimas para que os cidadãos tenham uma vida saudável, além da sua inserção social no sentido de promover a participação ativa de todos no cotidiano da vida em comunidade.

O direito ao Meio Ambiente equilibrado, alçado na Categoria de Direito Fundamental da Pessoa Humana, torna-se imprescritível e irrevogável, considerado como cláusula pétrea da Norma Constitucional, imune, portanto, a qualquer alteração normativa que se pretenda produzir.

Na busca da proteção do Direito ao Meio Ambiente equilibrado a Constituição da República Federativa do Brasil de 1988 impõe ampla proteção ao cidadão contra a degradação ambiental, inclui-se nesta tutela a Responsabilidade Penal Ambiental que se constitui em objeto de estudo no tópico seguinte.

\section{CONCEITO DE RESPONSABILIDADE PENAL AMBIENTAL}

Diniz conceitua Responsabilidade como “dever jurídico de 
responder por atos que indiquem dano a terceiro ou violação de norma jurídica". (DINIZ, 2008, p. 194).

Responsabilidade Penal Ambiental é a condição daquele que causa danos ambientais (o poluidor) ${ }^{11}$ de submissão às consequências jurídicas do ato ilícito na esfera penal da jurisdição. Justifica-se, assim, a imposição de sanções penais às agressões e à natureza.

Como preleciona Benjamin:

Se o Direito Penal é, de fato, última ratio na proteção de bens individuais (vida e patrimônio, por exemplo), com mais razão impõe-se sua presença quando se está diante de valores que dizem respeito à toda a coletividade, já que estreitamente conectados à complexa equação biológica que garante a vida humana no planeta. (BENAMIN, 1988, p. 391).

O fundamento legal da responsabilidade pelos danos ao Meio Ambiente consta do $\S 3^{\circ}$, do art. 225, da Constituição da República Federativa do Brasil, ao dispor: "As condutas e atividades consideradas lesivas ao meio ambiente sujeitarão os infratores, pessoas físicas ou jurídicas, a sanções penais e administrativas, independentemente da obrigação de reparar os danos causados." (BRASIL, 1988).

A norma dispõe que a preservação do Meio Ambiente é obrigação do Estado e da Coletividade. Todo aquele que atentar contra a preservação da natureza poderá sofrer sanções de ordem penal, civil e administrativa.

A responsabilidade de natureza penal, pela prática de condutas lesivas ao meio ambiente, encontra previsão na Lei $\mathrm{n}^{\circ}$ 9.605/98. Nessa esfera, a respectiva responsabilização do poluidor somente ocorre se houver a comprovação dos requisitos configuradores do Delito Ambiental.

11 O conceito de "poluidor", no art. $3^{\circ}$, inciso IV, da Lei ${ }^{\circ}{ }^{\circ} 6.938 / 81$, que expressa: "poluidor: a pessoa física ou jurídica, de direito público ou privado, responsável direta ou indiretamente por atividade causadora de degradação ambiental". (BRASIL, 1988). (BRASIL, 1988). p. 391). da Re autor). 
O segundo dispositivo desta lei ${ }^{12}$ especifica quais os agentes que podem ser responsabilizados pela prática de danos ambientais. Prevê a hipótese da incidência dos dispositivos legais à prática de crimes por ação ou omissão do agente. Quem tem a possibilidade de impedir a prática de delitos contra a natureza e não agir neste sentido poderá ser responsabilizado concomitantemente nas sanções penais previstas na legislação.

O legislador incluiu, ainda, a pessoa jurídica como passível de responder por ações penais, ao dispor no art. $3^{\circ}$ da citada lei:

As pessoas jurídicas serão responsabilizadas administrativa, civil e penalmente conforme o disposto nesta lei, nos casos em que a infração seja cometida por decisão de seu representante legal ou contratual, ou de seu órgão colegiado, no interesse ou benefício da sua entidade. (BRASIL, 1988). p. 391). da Re autor). Parágrafo único. A responsabilidade das pessoas jurídicas não exclui a das pessoas físicas, autoras, co-autoras ou partícipes do mesmo fato. (BRASIL, 1988).

O referido dispositivo legal ratifica o comando constitucional previsto no Art. 225, $\S 3^{\circ}$, que dispõe: "As condutas e atividades consideradas lesivas ao meio ambiente sujeitarão os infratores, pessoas físicas ou jurídicas, a sanções penais e administrativas, independentemente da obrigação de reparar os danos causados". (BRASIL, 1988).

Para reforçar a garantia da aplicação da lei penal aos agentes poluidores, a legislação ${ }^{13}$ ainda autoriza a desconstituição da pessoa jurídica quando esta se constituir em obstáculo para o ressarcimento de prejuízos causados ao Meio Ambiente.

12 “Art. $2^{\circ}$. Quem, de qualquer forma, concorre para a prática dos crimes previstos nesta Lei, incide nas penas a estes cominadas, na medida da sua culpabilidade, bem como o diretor, o administrador, o membro de conselho e de órgão técnico, o auditor, o gerente, o preposto ou mandatário de pessoa jurídica, que, sabendo da conduta criminosa de outrem, deixar de impedir a sua prática, quando podia agir para evita-la”. (BRASIL, 1988).

13 Art. 4. "Poderá ser desconsiderada a pessoa jurídica sempre que sua personalidade for obstáculo ao ressarcimento de prejuízos causados à qualidade do meio ambiente". (BRASIL, 1988). 
Atualmente, praticamente já se consolidou o entendimento no sentido de que as pessoas jurídicas podem ser responsabilizadas pela prática de crimes ambientais. Para pessoa jurídica, a lei 9.605/98 prevê, de acordo com o disposto no seu art. 22, as seguintes penas restritivas de direito: I. Suspensão total ou parcial das atividades; II. Proibição de contratar com o Poder Público e de obter subsídios, subvenções ou doações pelo prazo de até 10 anos. Além dessas medidas, poderão ainda ser aplicadas, de acordo com o art. 21, a multa e a prestação de serviços à comunidade. Esta última consiste em promover custeio de programas e projetos ambientais; execução de obras de recuperação de áreas degradadas; manutenção de espaços públicos; e contribuições a entidades ambientais ou culturais públicas. (BRASIL, 1988).

Após a promulgação da Constituição da República Federativa do Brasil de 1988 surge um suporte de ordem legal que se consolidou juridicamente na proteção do Meio Ambiente. Há de se ressaltar, também, a relevante contribuição para a doutrina e jurisprudência ao dispor sobre a Responsabilidade Penal da Pessoa Jurídica, cujo entendimento se consolidou mediante decisão do STF. ${ }^{14}$

\section{CONCLUSÃO}

Apesar da demora, felizmente a Sociedade está unindo esforços no sentido de amenizar a degradação do Meio Ambiente. Está mais consciente de que esta agressão compromete a qualidade de vida de toda a humanidade e até mesmo a sua existência. No sentido de pelo menos amenizar os efeitos dos danos que comprometem a Sustentabilidade impõe-se, além da sua conscientização e educação sobre os problemas, a difusão de mecanismos legais que existem à disposição do cidadão

14 STF/PR, RE 548181, j. 06.08.2013, rel. Min. Rosa Weber. 
para evitá-los.

A Constituição da República Federativa do Brasil de 1988 constitui-se numa das mais avançadas em termos de proteção ambiental, pois garantiu a Sociedade brasileira instrumentos coercitivos para garantia da tutela do Meio Ambiente.

Ao lado das responsabilidades, civil e administrativa, os agentes causadores de poluição poderão responder pela responsabilidade penal ou criminal pela prática de ilícitos contra o Meio Ambiente.

Cabe à Sociedade e ao Poder Judiciário unirem esforços no sentido de concretizar os mecanismos, de proteção ambiental, para fins de garantir o Meio Ambiente saudável a todos, nos exatos termos do disposto no art. 225 da Constituição da República Federativa do Brasil.

\section{REFERÊNCIAS}

BARROSO, Luís Roberto. A dignidade da pessoa humana no direito constitucional contemporâneo: a construção de um conceito jurídico à luz da jurisprudência mundial. Belo Horizonte: Fórum, 2014.

. Curso de direito constitucional contemporâneo: os conceitos fundamentais e a construção do novo modelo. 5. ed. São Paulo: Saraiva, 2015.

BENAMIN, Antonio Hermann V. Crimes contra o meio ambiente: uma visão geral. $12^{\circ}$ Congresso Nacional do Ministério Público. Fortaleza: Livro de Teses, 1988.

BESTER, Gisela Maria. A concepção de Constituição de Hermann Heller: integração normativa e sociológica e sua possível contribuição à teoria da interpretação constitucional. Revista da Faculdade de Direito da UFMG [recurso eletrônico], Belo Horizonte, n. 36, p. 231-250, 1999. Disponível em: <http://dspace/xmlui/bitstream/ item/12046/1064.pdf?sequence=1>. Acesso em: 10 jun. 2016.

BOBBIO, Norberto; MATTEUCI, Nicola; PASQUINO, Gianfranco. Dicionário de Política. 9. ed. Brasília: Universidade de Brasília, 1997.

BRASIL. Constituição da República Federativa do Brasil de 1988 (texto compilado). Presidência da República. Casa Civil - Subchefia para Assuntos Jurídicos. Brasília DF. Disponível em: <http://www.planalto.gov.br.> Acesso em: 10 jun. 2016.

CASTRO, Matheus Felipe de Castro; MEZZAROBA, Orides. História ideológica e econômica das constituições brasileiras. Belo Horizonte: Arraes, 2015. 
DINIZ, Maria Helena. Dicionário jurídico. 3. ed. São Paulo: Saraiva, 2008.

FREITAS, Juarez. Sustentabilidade: direito ao futuro. 2. ed. Belo Horizonte: Fórum, 2012.

GRAU, Eros Roberto. A ordem econômica na Constituição de 1988. 17. ed., São Paulo: Malheiros Editores, 2015.

HELLER, Hermann. Teoria do estado. Tradução de Lycurgo Gomes da Motta. São Paulo: Mestre Jou, 1968.

MELO, Osvaldo Ferreira de. Dicionário de política jurídica. Florianópolis, OAB-SC, 2000.

MORAES, Alexandre de. Constituição do Brasil interpretada e legislação constitucional. São Paulo: Atlas, 2002.

PASOLD, Cesar Luiz. Função social do estado contemporâneo. 4. ed. rev. ampl. Ebook. Itajaí: Univali, 2013. Disponível em: <http://siaiapp28.univali.br/LstFree.aspx >. Acesso em: 7 jul. 2016.

RODRIGUES, Marcelo Abelha. Instituições de direito ambiental. São Paulo: Max Limonad, 2002. v. 1.

SARLET, Ingo Wolfang. Dignidade (da pessoa) humana e direitos fundamentais na Constituição Federal de 1988. 10. ed. rev. e ampl. Porto Alegre: Livraria do Advogado, 2015.

SILVA, José Afonso da. Aplicabilidade das normas constitucionais. 2. ed. rev. e ampl. São Paulo: Revista dos Tribunais, 1982.

. Direito ambiental constitucional. 2. ed. 3. tir. São Paulo: Malheiros, 1998.

$\overline{\operatorname{ros}, 2014 .}$

Curso de direito constitucional positivo. 37. ed. rev. e atual. São Paulo: Malhei-

Artigo recebido em 30/05/2016

Artigo aprovado em 02/08/2016 